University of Navarra

\title{
DOES MORE MONEY BUY YOU MORE HAPPINESS?
}

\author{
Manel Baucells \\ Rakesh K. Sarin
}




\title{
DOES MORE MONEY BUY YOU MORE HAPPINESS?
}

\author{
Manel Baucells* \\ Rakesh K. Sarin**
}

\section{Abstract}

Why do we believe that more money will buy us more happiness (when in fact it does not)? In this paper, we propose a model to explain this puzzle. The model incorporates both adaptation and social comparison. A rational person who fully accounted for the dynamics of these factors would indeed buy more happiness with money. We argue that projection bias, the tendency to project our current reference levels into the future, precludes subjects from correctly calculating the utility obtained from consumption. Projection bias has two effects. First, it makes people overrate the happiness that they will obtain from money. Second, it makes people misallocate their consumption budget by consuming too much at the beginning of the planning horizon, or consuming too many adaptive goods.

* Professor of Managerial Decision Sciences, IESE.

** Professor of Decisions, Operations \& Technology Management, UCLA Anderson School of Management.

Keywords: Happiness, Life Satisfaction, Habituation, Social Comparison, Consumer Life-Cycle Planning, Projection Bias. 


\section{DOES MORE MONEY BUY YOU MORE HAPPINESS?.}

\section{Introduction}

"We hold these truths to be self-evident, that all men are created equal, that they are endowed by their Creator with certain unalienable Rights, that among these are Life, Liberty and the pursuit of Happiness."

- The Declaration of Independence, July 4, 1776

In this paper, we propose a model of adaptation and social comparison that provides insight into the following puzzle:

Why do we believe that more money will buy us more happiness (when in fact it does not)?

The key argument is that people overrate the impact money will have on improving happiness (well-being). They do this because they do not fully account for the adaptation to a higher standard of living that accompanies their higher level of income. Further, a permanent increase in income for all peers (e.g., a company-wide pay raise) leaves an individual in the same social position as before the increase. These two forces, adaptation and social comparison, make it difficult to raise the average well-being of society through economic growth alone.

Some segments of the population may indeed benefit from economic growth. For example, nouveau riche people who move from a lower income group to a higher income group will show a higher level of well-being (at least temporarily). Sophisticated individuals who fully account for adaptation and social comparison can also benefit from economic growth, as they will keep consumption low in early periods in order to be able to sustain an increasingly accelerated consumption plan.

In Section 2, we present our model in which the overall utility of a consumption stream depends on relative consumption with respect to a reference level of consumption. The

* The authors are thankful to Professor Steven Lippman (UCLA) for his helpful suggestions. 
reference level itself is influenced by one's past consumption (adaptation) and the average consumption of one's peer group (social comparison).

In Section 3, we show that our model is consistent with the two key findings in the well-being literature. These findings are: [1] happiness scores in developed countries are flat in spite of considerable increases in average income; and [2] there is a positive relationship between individual income and happiness within a society at any given point in time.

In Section 4, we derive the optimal consumption plan using our model and show how a rational individual will plan consumption over time. We also derive the indirect utility of income under the assumption of optimal planning. This utility indeed increases with income.

In Section 5, we resolve the puzzle posed at the start of our paper using evidence from psychology that shows that people underestimate the effects of adaptation, which causes them to overestimate the utility that will be derived from a permanent increase in income.

We make a distinction between basic goods and adaptive goods. Basic goods (food, social relationships, sleep) exhibit little or no adaptation. In Section 6, we show why people tend to allocate higher than optimal income to adaptive goods, at the expense of basic goods.

Finally in Section 7, we conclude our findings and provide some implications of our model for economic policy and well-being research.

\section{Adaptation - Social Comparison Model}

Suppose $\left(x_{1}, x_{2}, \ldots, x_{T}\right)$ is a consumption stream, where $x_{t}$ is the consumption in period $t$. What is the total utility that an individual (consumer) obtains from such a stream? The Discounted Utility (DU) Model proposes evaluating total utility as:

$$
V\left(x_{1}, \ldots, x_{T}\right)=\sum_{t=1}^{T} \delta^{t-1} v\left(x_{t}\right)
$$

Where $v\left(x_{t}\right)$ is the utility of consuming $x_{t}$ in period $t$, and $\delta^{t}$ is the discount factor associated with period $t$.

The DU Model assumes consumption independence, which means that the utility derived from present consumption is not affected by past consumption (Samuelson, 1937; Koopmans, 1960). It is easy to see that in the DU Model an increase in income permits a higher level of consumption and, therefore, total utility will indeed increase as income increases. For a concave $v$, gains in total utility will be smaller and smaller as income increases.

In Figure 1, average happiness is plotted against income per capita for several countries. Several books discuss the measurement and empirical issues dealing with happiness within a country and across countries (Kahneman, Diener, and Schwarz, 1999; Van Praag and Ferrer i Carbonell, 2004; Frey and Stutzer, 2002a; Layard, 2005). It is clear from this figure that average happiness in poorer countries is lower than that in wealthier countries. Political issues such as democracy, freedom and individual rights also influence happiness, which is distinctly lower in former communist countries (Frey and Stutzer, 2002a). 
In wealthier societies the basic needs of the people are, by and large, satisfied. In poorer countries, progress is needed to address the problems of hunger, shelter, disease and in some cases social turmoil caused by war and violence. It is therefore not a surprise that average happiness is lower in poorer countries. The happiness curve in Figure 1 is consistent with the diminishing marginal utility of income. Beyond a certain level of income, say $\$ 15,000$ per year, happiness does not increase much with income.

\section{Figure 1}

Country Comparison of Income and Happiness

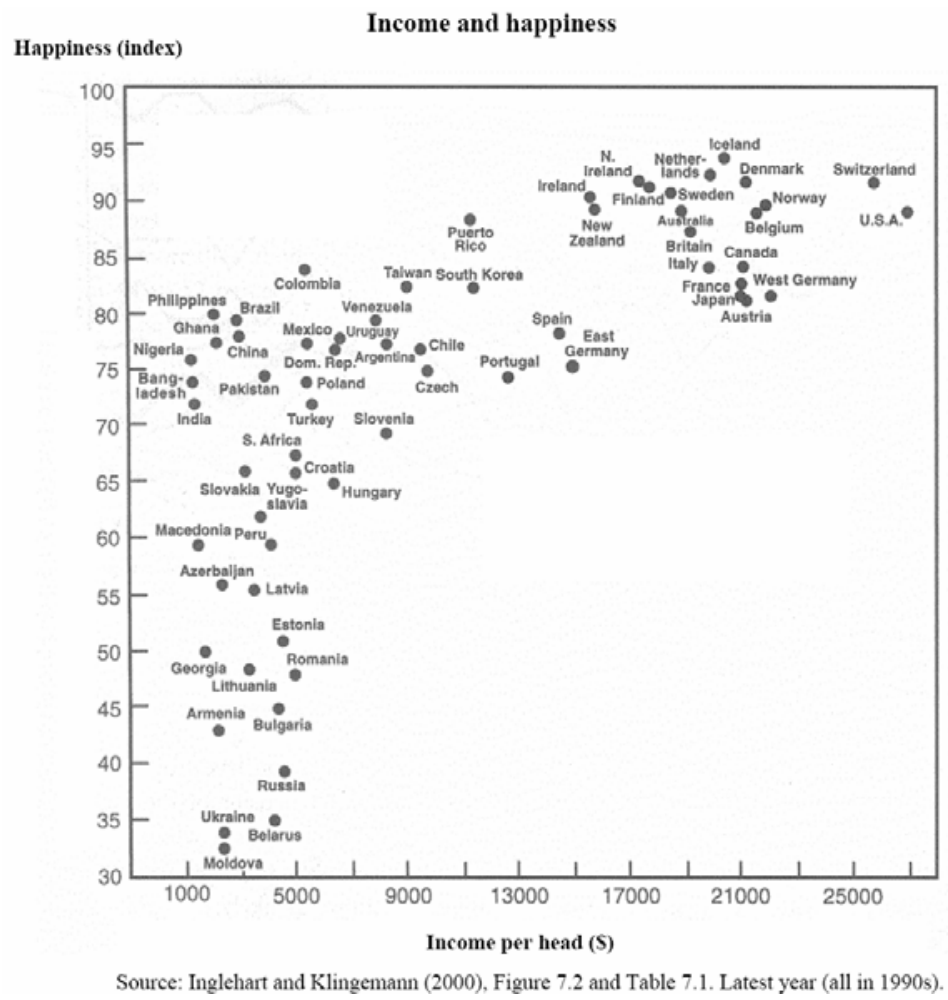

Easterlin (1974, 2001) has argued that happiness has not increased over time in spite of significant increases in real income per capita in wealthier nations. Easterlin's hypothesis of "no" marginal utility cannot be supported by the DU Model. Further, consumption independence - a crucial assumption of the DU Model - is not supported by empirical and behavioral studies (Loewenstein, Read and Baumeister, 2003).

There is considerable evidence that the utility derived from consumption depends crucially on two fac- tors: [1] adaptation or habituation to previous consumption levels, and [2] social comparison with a reference or peer group (Layard, 2005; Frederick and Loewenstein, 1999; Frank, 1985, 1997, 1999; Easterlin, 1995; Brickman, Coates, and Janoff-Bullman, 1978; Clark, 1996).

A woman who drives a rusty old compact car as a student may find temporary joy upon acquiring a new sedan when she lands her first job, but she soon adapts to driving the new car and assimilates it as a part of her lifestyle. Brickman, Coates, and J anoff-Bullman (1978) find 
that lottery winners report only slightly higher levels of life satisfaction than the control group just a year after their win (4.0 versus 3.8 on a 5-point scale). Clark (1996) finds evidence that job satisfaction - a component of well-being - is strongly related to changes in pay, but not levels of pay. A crucial implication of adaptation is that the utility derived from the same $\$ 3,000$ per month worth of consumption is quite different for someone who is used to consuming that amount of goods and services than for someone who is used to consuming only $\$ 2,000$ per month. ${ }^{1}$

Several authors have proposed models that account for adaptation in the determination of the total utility of a consumption stream (Ryder and Heal, 1973; Pollak, 1970; Wathieu, 1997, 2004). Baucells and Sarin (2006b) incorporate satiation from past consumption in a modification of the DU model.

In addition to adaptation, the utility derived from consumption also depends on the consumption of others in a person's peer group. Driving a new Toyota sedan when everyone else in the peer group drives a new Lexus sedan seems quite different than if others in the peer group drove economy cars. Frank $(1985,1997)$ provides evidence from the psychological and behavioral economics literature that well-being or satisfaction depends heavily on social comparison. Solnick and Hemenway (1998, Table 2) asked students

in the School of Public Health at Harvard to choose between living in one of two imaginary worlds in which prices were the same:

1. In the first world, you get $\$ 50,000$ a year, while other people get $\$ 25,000$ a year (on average).

2. In the second world, you get $\$ 100,000$ a year, while other people get $\$ 250,000$ a year (on average).

A majority of students choose the first type of world.

People are likely to compare themselves with those who are similar in income and status. A university professor is unlikely to compare herself with a movie star or a homeless person. She will most likely compare her lifestyle to those of other professors at her university and similarly situated colleagues at other, comparable universities. Medvec, Madey and Gilovich (1995) find that Olympic bronze medalists are happier than Olympic silver medalists, as the former compare themselves to the athletes who got no medal at all, whereas the latter have nightmares of missing the gold. After the unification of Germany, East Germans' level of happiness fell as their comparison group shifted from people in other former Soviet block countries to people from West Germany (Layard, 2005). Morawetz (1977) found that people living in a community where variation in income is small are happier than those living in a community with a higher absolute income, but a more unequal income distribution. It is possible that in a recession or downturn, when everyone gets a uniform pay cut, happiness may not go down, but in prosperity, differential increases in pay can cause unhappiness.

We cannot, however, simply improve our happiness by imagining more unfortunate individuals. Kahneman and Miller (1986) assert that to influence our hedonic state, counterfactuals must be plausible, not just possible alternatives to reality. The all-too-common

\footnotetext{
${ }^{1}$ People may not fully adapt to unemployment, loss of a spouse, noise and other unfortunate and stressful situations. The adaptation rate is high for material goods, but a healthy marriage or good social relationships provide undiminished joy.
} 
tactic of parents coaxing a child to appreciate food by reminding them of starving children in Africa does not work. Instead, the same child will be far more likely to appreciate a warm apple cider after a little league game in the cold (Parducci, 1995).

We note that it is possible that through spiritual practices such as meditation or prayer, one might gain a better perspective on life and reduce the harmful effects of comparison; however, such a practice requires considerable time, effort and discipline. For this study, we assume that the social comparison level is exogenously specified; though a theory where the appropriate peer group and social comparison level is endogenous would be useful.

We now state our model of adaptation and social comparison:

$$
\begin{gathered}
V\left(x_{1}, \ldots, x_{T}\right)=\sum_{t=1}^{T} \delta^{t-1} v\left(x_{t}-r_{t}\right), \\
r_{t}=\sigma s_{t}+(1-\sigma) a_{t}, t=1, \ldots, T, \\
a_{t}=\alpha x_{t-1}+(1-\alpha) a_{t-1}, t=2, \ldots, T,
\end{gathered}
$$

$a_{1}$, and $s_{t}, t=1, \ldots, T$, are given.

In the above model, $r_{t}$ is the reference level in period $t$. The reference level is a convex combination of social comparison level, $s_{t}$, and adaptation level, $a_{t}$. The adaptation level is the exponentially weighted sum of past consumption, in which recent consumption levels are given greater weight than more distant past consumption levels. ${ }^{2}$ We interpret total utility, $V$, as a measure of happiness over an extended period. Experienced utility or per period utility, $v$, is to be interpreted as a measure of happiness in the period of time under consideration (Kahneman, Wakker, and Sarin, 1997). Occasionally, in order to remove the effects of initial values, we will use the long-run values of experienced utility as a measure of happiness. If st is assumed to be constant over time, then we use $\mathrm{S}$ to denote the social comparison level.

The carrier of utility is the gain or loss from the reference level. The reference level is determined by both past consumption and the social comparison level. Consider an example in which an individual has been consuming 6 units per period and his adaptation level has settled to 6 units. The average consumption level of his peer group is 10 units, and his social comparison level is simply the mean consumption of his peer group (10 units). Now the reference level for this individual, assuming $\sigma=0.5$, will be $0.5 \times 6+0.5 \times 10=8$ units. If this individual were to consume 8 units, then the corresponding utility will be at the neutral level,

\footnotetext{
${ }^{2}$ Note that $x-r$ can be written as $x-\sigma s-(1-\sigma) a=\sigma(x-s)+(1-\sigma)(x-a)$. This last expression can be interpreted as an individual who uses not one $(r)$ but two reference points ( $s$ and $a$ ). The comparison of $x$ with $s$ receives weight $\sigma$, and the comparison with a receives weight $1-\sigma$. Because $a$ is also a convex combination of past consumption levels, one can interpret that each level of past consumption serves as reference point, with different weights given to each comparison. Similarly, if $s$ is understood as an average consumption in the society or in the peer group, then $x-s$ could be seen as a multiple comparison with each group member.
} 
$v(8-8)=v(0)=0$. If he consumes more than 8 units, then the utility of current consumption will be positive; if he consumes less than 8 units, then the utility will be negative.

When $\sigma=1$, utility is determined solely by social comparison. Similarly, when $\sigma=0$, social comparison plays no role and utility is determined solely by adaptation. The relative weight given to adaptation and social comparison is likely to be domain specific. For example, social comparison for family life may play little to no role, as one does not readily observe this aspect of one's peers' lives. The utility one derives from a car, house, vacation or private school for children, however, is likely to be influenced by social comparison.

The speed of adaptation is governed by $\alpha$. For $\alpha=1$ the adaptation is immediate and the most recent consumption will always serve as the adaptation level. For $\alpha=0$, there is no adaptation and the initial adaptation level, $a_{1}$, serves as the reference adaptation in every period regardless of past consumption. Goods for which $\alpha=0$ are called basic goods. Examples of basic goods include food, sleep, friendships and shelter. These goods are necessary for survival. ${ }^{3}$ The study of basic goods and their contribution to well-being is not irrelevant, as a large percentage of the world population lives at subsistence level. For these people, more money, and therefore the provision of adequate food, shelter, clean water and health, could indeed improve happiness.

The utility function, $v$, is assumed to be concave for consumption above the reference level and convex for consumption below the reference level (Kahneman and Tversky, 1979). The neutral utility, $v(0)=0$, is realized when consumption equals the reference level. In the next section, we explore the relationship between income and happiness in more depth. In all our numerical examples, we assume $v(x)=x^{\beta}, x \geq 0$, and $v(x)=-\lambda|x|^{\beta}, x<0$, with $\beta=0.5$ and $\lambda=2.25$. The parameter $\lambda$ measures the degree of loss aversion. With $\lambda=2.25$, a $\$ 10$ loss gives the same magnitude of negative utility as a $\$ 22.5$ gain.

\section{Income- Happiness Relationship}

"A very poor, underprivileged person might think that it would be wonderful to have an automobile or a television set, and should he acquire them, at the beginning he would feel very happy. Now if such happiness were something permanent, it would remain forever. But it does not; it goes. After a few months he wants to change the models. The old ones, the same objects now cause dissatisfaction. This is the nature of change."

- Path to Tranquility, Dalai Lama, p. 175

The above quote captures the essence of the "Easterlin Paradox," which is an empirical finding that happiness scores have remained flat despite considerable increases in average income. The most striking example is J apan, where a five-fold increase in real per capita income has led to virtually no increase in average life satisfaction (Figure 2). A similar pattern holds for the United States (Figure 3) and for most other developed countries.

\footnotetext{
${ }^{3}$ For rich people or those in developed countries, food becomes an adaptive good used for social status (fine wine or a fancy restaurant) and not merely for nutrition.
} 


\section{Figure 2}

Satisfaction with Life and Income Per Capita in Japan between 1958 and 1991

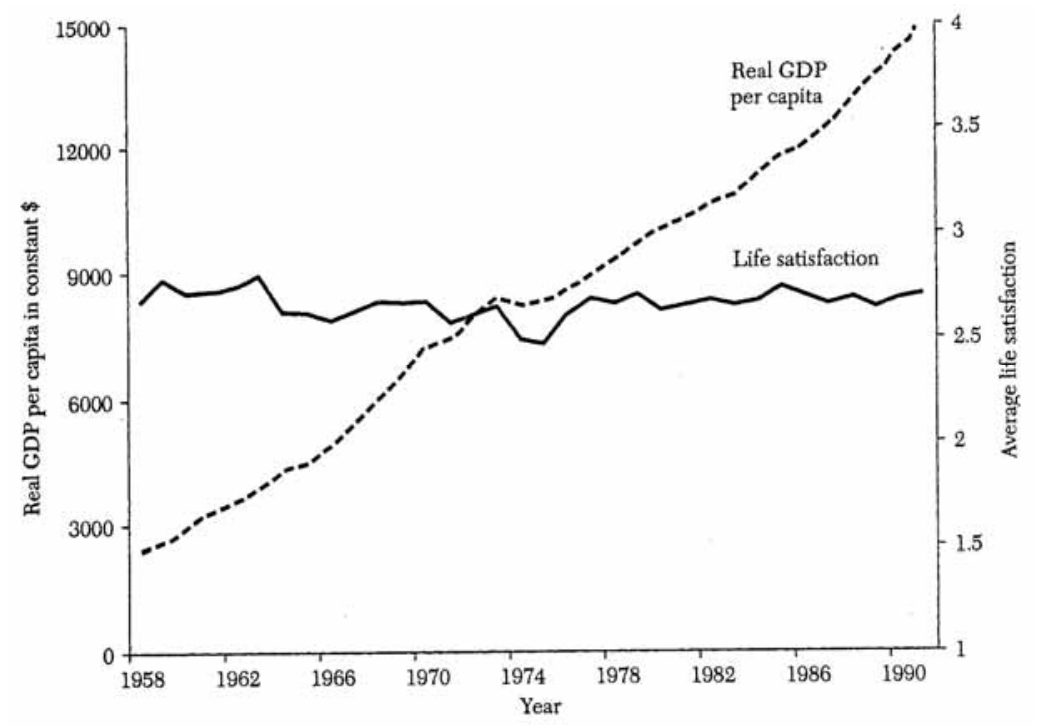

Happiness in these surveys is measured by asking people how satisfied they are with their lives. A typical example is the General Social Survey (Davis, Smith, and Marsden, 2001) which asks: "Taken all together, how would you say things are these days - Would you say that you are very happy, pretty happy, or not too happy?" In World Values Survey, Inglehart and colleagues (2000) use a 10-point scale, with one representing dissatisfied and 10 representing satisfied, to measure well-being. Pavot and Diener (1993) use five questions, each rated on a scale from one to seven, to measure life-satisfaction (Table 1).

\section{Table 1}

The Satisfaction with Life Scale (Pavot and Diener, 1993)

DIRECTIONS: Below are five statements with which you may agree or disagree.

Using the 1-7 scale below, indicate your agreement with each item by placing the appropriate number in the line preceding that item. Please be open and honest in your responding.

1 = Strongly Disagree; 2 = Disagree; 3 =Slightly Disagree; 4 = Neither Agree nor Disagree; 5 = Slightly Agree; 6 = Agree; 7 = Strongly Agree

a) In most ways my life is close to my ideal.

b) The conditions of my life are excellent.

c) I am satisfied with my life.

d) So far I have gotten the important thing I want in life.

e) If I could live my life over, I would change almost nothing. 
Davidson, Jackson, and Kalin (2000) and Davidson and colleagues (2003) have found that when people are cheerful and experience positive feelings (funny film clips), there is more activity in the left front section of the brain. The difference in activity between the left and right sides of the prefrontal cortex seems to be a good measure of happiness. Self reported measurements of happiness correlate with this measure of brain activity, as well as with the ratings of one's happiness made by friends and family members (Lepper, 1998). Diener and Tov (2005) report that subjective measures of well-being correlate with other types of measurements of happiness such as biological measurements, informant reports, reaction time, open ended interviews, smiling and behavior and online sampling. Kahneman, Krueger, Schkade, Schwarz, and Stone (2006) discuss biases in measuring well-being that are induced by a focusing illusion in which the importance of a specific factor (income, marriage, health) is exaggerated by drawing attention to the factor. Nevertheless, Kahneman and Krueger (2006) argue that self-reported measures of well-being may be relevant for future decisions as the idiosyncratic effect are likely to average out in representative population samples. Frey and Stutzer (2002b) conclude: "The existing research suggests that, for many purposes, happiness or reported subjective well-being is a satisfactory empirical approximation to individual utility."

\section{Figure 3}

Income and Happiness in the United States

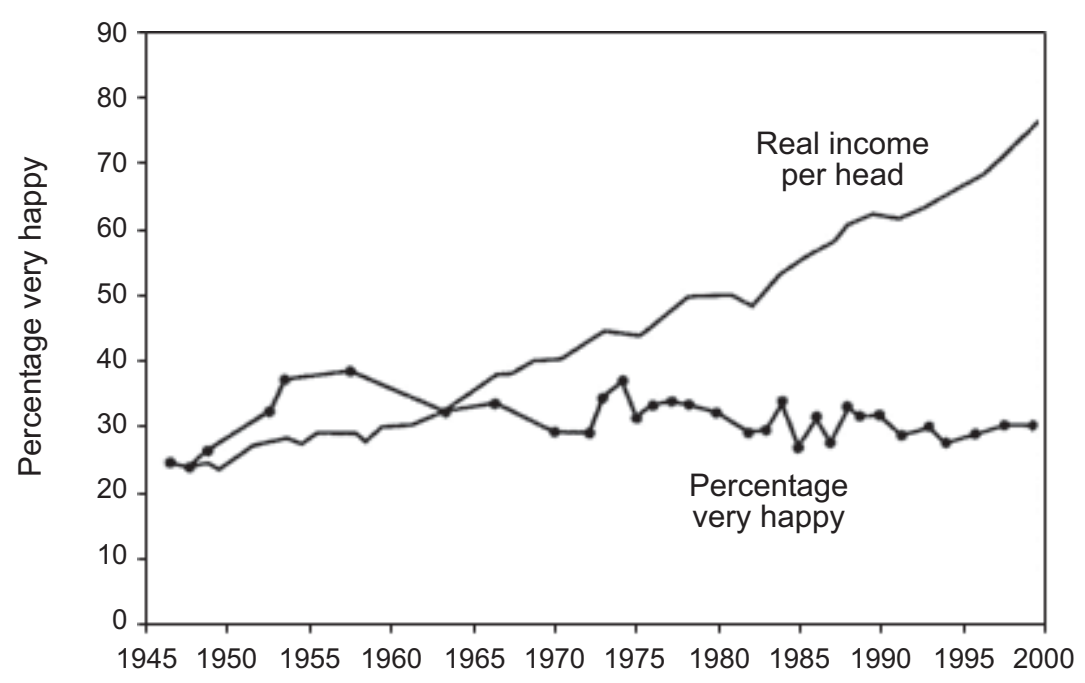

Source: Layard (2005).

If people pursue the goal of maximization of happiness and they report their happiness levels truthfully in the variety of surveys discussed above, then how do we explain that happiness scores have remained flat in spite of significant increases in real income over time? Of course, happiness depends on factors other than income such as the genetic makeup of a person, family relationships, community and friends, health, work (unemployment, job security), external environment (freedom, wars or turmoil in society, crime) and personal values (perspective on life, religion, spirituality). Income, however, does influence a person's happiness up to a point, and has a moderating effect on the adverse effects of some life events (Smith, Langa, Kabeto, and Ubel, 2005). As shown in Figure 4 mean happiness for a cross-section of Americans does increase with income, though at a diminishing rate. In fact, in any given society, richer people are substantially happier relative to poorer people (see Table 2 for United States and Britain). 


\section{Figure 4}

Mean Happiness and Real Household Income for a Cross-Section of Americans in 1994

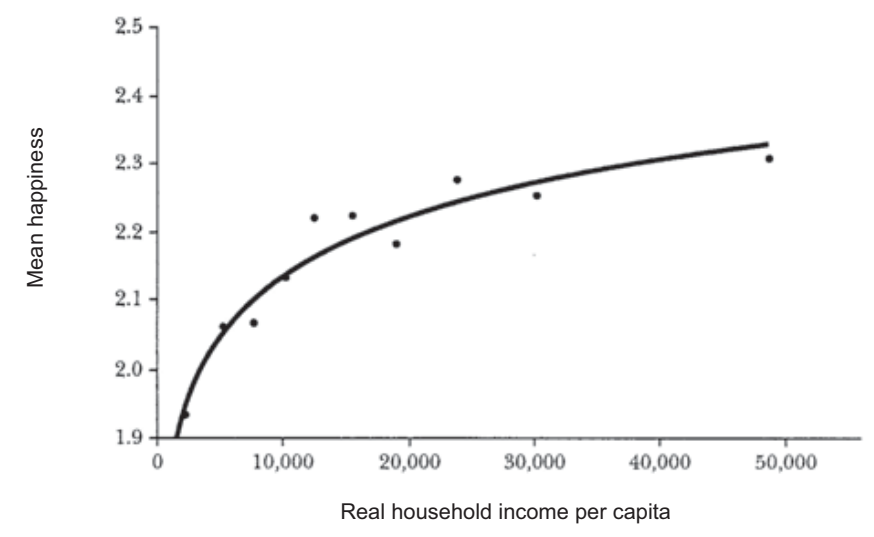

Source: diTella and MacCullouch (2006).

Our model of adaptation and social comparison is consistent with the joint empirical finding that happiness over time does not increase appreciably in spite of large increases in real income, but happiness in a cross-section of data does depend on relative levels of income.

\section{Table 2}

Happiness According to Income Position

\begin{tabular}{|c|c|c|c|c|}
\hline \multirow[b]{2}{*}{$(\%)$} & \multicolumn{2}{|c|}{ United States } & \multicolumn{2}{|c|}{ Britain } \\
\hline & $\begin{array}{c}\text { Tob } \\
\text { Quarter }\end{array}$ & $\begin{array}{l}\text { Bottom } \\
\text { Quarter }\end{array}$ & $\begin{array}{c}\text { Top } \\
\text { Quarter }\end{array}$ & $\begin{array}{l}\text { Bottom } \\
\text { Quarter }\end{array}$ \\
\hline Very happy & 45 & 33 & 40 & 29 \\
\hline Quite happy & 51 & 53 & 54 & 59 \\
\hline Not too happy & 4 & 14 & 6 & 12 \\
\hline & 100 & 100 & 100 & 100 \\
\hline
\end{tabular}

Source: Layard (2005).

That rich people are happier than poor people at a given time and place is easy to justify by social comparison. By and large, richer people have a favorable evaluation of their own situation compared to others. In contrast, the economically disadvantaged will have an unfavorable evaluation of their relative position in the society. Needless to say, some rich people may bring misery upon themselves by comparing themselves with even richer people. Over time, though, both rich and poor people have significantly improved their living standards, but neither group has become happier. Adaptation explains this paradoxical finding.

Consider Mr. Yoshi, a young professional living in Japan in the 1950s. He was content to live in his parents' house, drive a used motorcycle for transportation, wash his clothes in a sink and listen to the radio for entertainment. Also consider Ms. Yuki, a young professional living in Japan in the 1990s. She earns five times the income of Mr. Yoshi in real terms. She wants her 
own house, own automobile, washing machine, refrigerator and television. She travels abroad for vacation and enjoys expensive international restaurants. Mr. Yoshi was consuming 10 units of income per period, but had adapted to that level of consumption. Ms. Yuki consumes 50 units of income per period and has adapted to consuming at that high level. Because Mr. Yoshi and Ms. Yuki are in similar social positions for their times, then both will have the same level of happiness. Happiness does not depend on the absolute level of consumption, which is substantially higher for Ms. Yuki. Instead, happiness depends on the level of consumption relative to the adaptation level. Ms. Yuki has adapted to a much higher level of consumption and therefore finds that she is no happier than Mr. Yoshi. Note that experienced utility, $v(x-r)$ (remains constant if income $\mathrm{x}$ increases from 10 units (Mr. Yoshi) to 50 units (M s. Yuki) in steps of one unit each year because $r$ also increases in steps of one unit each year. ${ }^{4}$

To demonstrate the role of adaptation and social comparison in determining utility experienced, we apply our model to the simple case of constant consumption plans. Suppose the social comparison level, $S$, and the initial adaptation level, $a_{1}$, are both 10 units. The experienced utility in each period for persons $A, B$ and $C$ who have a constant consumption of 12,10 and 8 units, respectively, is plotted in Figure 5 . Figure $5 c$ shows that the poor person, $C$, will feel less dissatisfaction over time; whereas, the richer person, A, will experience diminished satisfaction. Both the poor and the rich person are adapting to their respective levels of consumption.

\section{Figure 5}

The Effect of Adaptation and Social Comparison on Experienced Utility. Panel (a) shows adaptation alone $(\alpha>0, \sigma=0)$, Panel (b) exhibits social comparison alone $(\sigma=1)$, and Panel (c) is a combination of adaptation and social comparison $(\alpha>0,0<\sigma<1)$. yyy-a

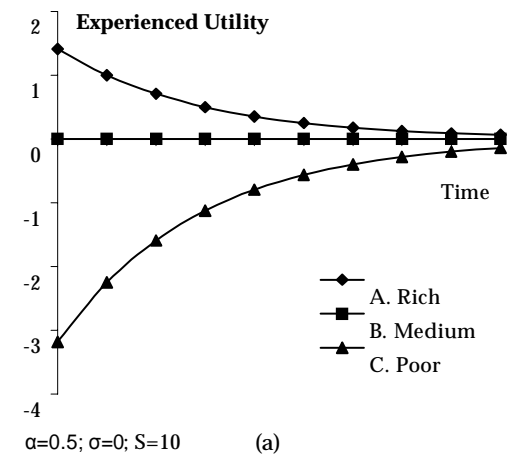

Two observations from Figure 5 are of special interest. First, with adaptation $(\alpha>0, \sigma=0$, Figure 5a) both the poor person, $C$, and the rich person, $A$, will converge to the neutral level of happiness as each becomes adapted to their own past consumption level. Second, with social comparison alone $(\sigma=1$, Figure $5 b)$, the poor person, $C$, and the rich person, A, will remain far apart in happiness. More generally, dispersion in happiness will be about the same as the dispersion in income. This is also the prediction of the Discounted Utility Model, which is a particular case of the pure social comparison model with $S=0$.

\footnotetext{
${ }^{4}$ If income increases at a geometric rate, say $4 \%$ per year, then he same conclusion is reached assuming income is
measured in logs as suggested by Layard (2005). In this case, use $v(\operatorname{In}(x)-\operatorname{In}(r))=\tilde{v}(x / r)$ instead of $v(x-r)$ in $(1)$,

${ }^{4}$ If income increases at a geometric rate, say $4 \%$ per year, then he same conclusion is reached assuming income is
measured in logs as suggested by Layard (2005). In this case, use $v(\operatorname{In}(x)-\operatorname{In}(r))=\tilde{v}(x / r)$ instead of $v(x-r)$ in $(1)$, and maintain the updating equations (2) and (3). and maintain the updating equations (2) and (3).
}

10 - IESE Business School-University of Navarra 
Together, the two factors of adaptation and social comparison provide the more realistic prediction that the discrepancy in reference levels, and therefore in happiness, is less than the discrepancy in income. The reference levels are pulled towards the average consumption (12, 10 , or 8 ), but do not converge to the average consumption because of the permanent social comparison with $S=10$. This prediction of our model is consistent with Easterlin, (1995, p. 42) who states that "the dispersion in norms [reference levels] appears to be, on average, less than that in incomes."

In Figure 6, the relationship between income and happiness is plotted for various weights, $\sigma$, on social comparison. We assume the initial adaptation and social comparison levels to be 10 . The horizontal axis represents the constant consumption level, $x$. Note that $v(x-r)=0$ at $x=r=10$. The vertical axis represents the long-run experienced utility, once the adaptation level has converged to $x$ (assuming $\alpha>0$ ).

By (2), the reference level, $r$, tends to $\sigma 10+(1-\sigma) x$, and therefore $x-r$ tends to $\sigma(x-10)$. Thus, the long-run experienced utility is given by $v(\sigma(x-10))$. In the absence of social comparison $(\sigma=0)$, the long-run experienced utility is independent of income and flat at zero. As the weight on social comparison increases, the richer people $(x>10)$ become happier and the poorer people $(x<10)$ become less happy. The happiness function is S-shaped and steeper for Iosses. Thus, for any rich person, say with $x=17$, there is a symmetric poor person, at $x=3$, such that an increase in income of the poor person gives higher utility than increasing the income of the rich one. If individuals are equally weighted (utilitarian view), then the greatest gain in societal happiness is realized by improving the income of the person who is slightly below the average. If the worse-off individuals receive higher weight (rank utilitarian view) then this may not be the case.

In Figure 6, we have assumed that the social comparison level is the same for a rich person as it is for a poor person. If, however, the peer group against which the social comparison is made changes with income level, then little gain in happiness may be realized. For example, if rich people compare themselves with other rich people, then $S=x$ and experienced utility becomes zero. The double edged sword of increasing adaptation level and increasing social comparison level may leave happiness unchanged even when income increases substantially. Conversely, if poor people are able to suppress social comparison, or compare themselves more often with even poorer individuals, then they may be able to partially overcome the predictions of Figure 6 . 


\section{Figure 6}

The Effect of Social Comparison on Long-run Experienced Utility

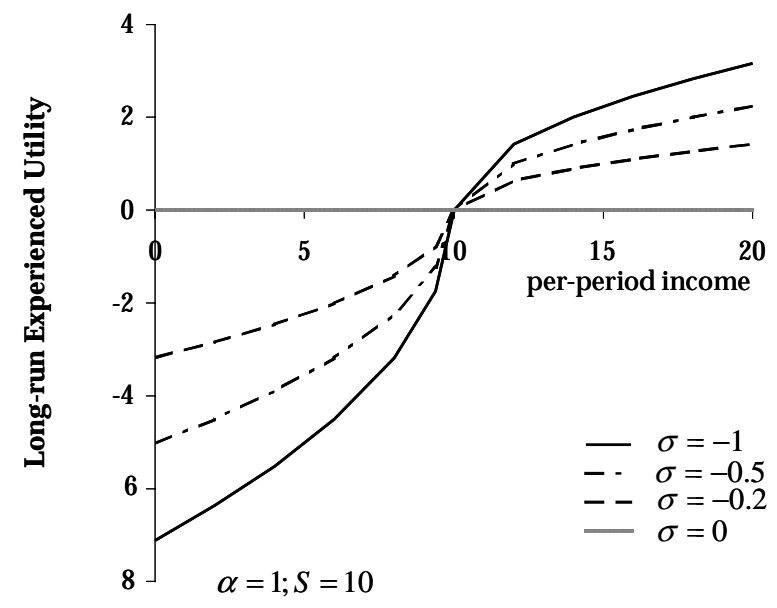

The argument above does not prove that a rational person who optimally plans consumption by anticipating future adaptation levels will not be happier with more money. We merely have asserted above that if society becomes accustomed or adapted to higher levels of consumption as incomes rise (which will occur if the consumption plan is constant or not sufficiently increasing), then there will be no gain in observed happiness scores. We now examine the optimal consumption plan for the Adaptation-Social Comparison Model.

\section{Optimal Consumption Plan}

Suppose that a consumer wishes to optimally allocate an income, $I$, over consumption periods $t=1, \ldots, T$. For simplicity, assume $\delta=1$ (no discounting), a constant unit price, and borrowing and saving at $0 \%$ interest. The consumer chooses $\left(x_{1}, \ldots x_{T}\right)$ to solve the following optimization problem:

$$
\begin{gathered}
\operatorname{Max} \quad V\left(x_{1}, \ldots x_{T}\right)=\sum_{t=1}^{T} v\left(x_{t}-r_{t}\right) \\
\text { s.t. } \\
\sum_{t=1}^{T} x_{t} \leq I \\
x_{t} \geq 0, t=1, \ldots, T
\end{gathered}
$$

and $r_{t}$ satisfying the updating equations (2) and (3).

The optimal consumption plan for the Discounted Utility Model is constant with $x_{t}=I / T, t=1, \ldots, T$. For our Adaptation-Social Comparison Model, the optimal consumption plan depends on reference levels. Since reference levels are influenced by both adaptation and social comparison, the optimal consumption plan shows a richer pattern. For the general case, 
we can always solve the mathematical program (4)-(6) to obtain the optimal consumption plan and the associated levels of per-period experienced utilities and total utility.

To explicitly solve (4)-(6), it is convenient to define $z_{t}=x_{t}-r_{t}$. We can then simply redefine the problem as one of finding the optimal values of $z_{t}$, as in the Discounted Utility Model, but with a modified budget constraint. To calculate the new budget constraint, note that for given values of $z_{t}$, one can easily recover the values of $x_{t}$ (and of $r_{t}$ and $a_{t+1}, t=1, \ldots, T$, in a recursive manner by means of (2) and (3). Hence, each $x_{t}$ is a function of $z_{\tau}, \tau=1, \ldots, t$. Therefore, the budget constraint (5) can be written in terms of $z_{t}, t=1, \ldots, T$. Such an expression for the budget constraint, however, is quite involved for the general model.

It is possible to obtain a tractable expression for the special case of $\alpha=1$. In this case, $r_{t}=\sigma s_{t}+(1-\sigma) x_{t-1}, \quad s o$ that $x_{t}=z_{t}+r_{t}=z_{t}+\sigma s_{t}+(1-\sigma) x_{t-1}, x_{t-1}=z_{t-1}+\sigma s_{t-1}+(1-\sigma) x_{\mathrm{t}-2}, \quad \ldots, \quad$ and $x_{1}=z_{1}+\sigma s_{1}+(1-\sigma) a_{1}$. It follows that:

$$
x_{t}=(1-\sigma)^{t} a_{1}+\sum_{\tau=1}^{T}(1-\sigma)^{t-\tau}\left(z_{\tau}+\sigma s_{\tau}\right) .
$$

Plugging (7) into (5) yields the desired expression for the budget constraint as a function of $z_{\mathrm{t}}$ :

$$
\left(K_{0}-1\right) a_{1}+\sum_{t=1}^{T} K_{t}\left(z_{t}+\sigma s_{t}\right) \leq I,
$$

Where

$$
K_{t}=\sum_{\tau=1}^{T-t+1}(1-\sigma)^{T-t+1-\tau}=\frac{1-(1-\sigma)^{T-t+1}}{\sigma}, t=0, \ldots, T
$$

Using standard calculus, the first order condition is given by:

$$
v^{\prime}\left(z_{t}\right)=\lambda k_{t}, t=1, \ldots, T \text {. }
$$

Where $\lambda$ is the Lagrange multiplier associated with (8).

Tf the constraint $x_{t}>0$ is met and $v$ is concave, then the optimal solution is unique and is given by the solution of (10). This will also be the case if $v$ is S-shaped, and the solution operates in the gains portion of the value function, i.e., $z_{t} \geq 0$; otherwise, there may be multiple local optimal solutions.

To gain further insights, we consider the case of a power value function, $v(z)=z^{\beta}, z \geq 0$. In this case, $v^{\prime}(z)=\beta / z^{1-\beta}$, and (10) becomes 


$$
z_{t} \geq\left(\frac{\beta}{\lambda k_{t}}\right)^{\frac{1}{1-\beta}}, t=1, \ldots, T
$$

Using the budget constraint (8), we solve for the Lagrange multiplier and finally obtain

$$
z_{t} \geq \frac{I-\sigma \Omega-\left(k_{0}-1\right) a_{1}}{k_{t}^{1 /(1-\beta)} K}, t=1, \ldots, T
$$

Where $\Omega=\sum_{t=1}^{T} K_{t} S_{t}$ and $K=\sum_{t=1}^{T} k_{t}^{-\beta /(1-\beta)}$. Using (7) now yields $x_{t}, t=1, \ldots, T$.

It is apparent from (12) that to ensure a level of consumption above the reference level $\left(z_{t} \geq 0\right)$ it is necessary for the social comparison levels and the initial adaptation level to be sufficiently low. Essentially, one needs to ensure that the numerator of (12) stays positive, or $\sigma \Omega+\left(k_{0}-1\right) a_{1} \leq I$. Two special cases with $\sigma=0$ and $\sigma=1$ are instructive. When $\sigma=0$, average income per period, $I / T$, above the initial adaptation level $a_{1}$ ensures consumption above the reference level in the remaining periods. When $\sigma=1$, the total income greater than $\sum_{t=1}^{T} s_{t}$ will also ensure that consumption in each period is above the ference level. Of course, if the level of social comparison is constant over time $\left(s_{1}=s_{2}=\ldots=s_{T}=S\right)$, this last condition reduces to average income per period greater than $\mathrm{S}$.

Even though (12) is derived using a power form for the value function, the conclusion that $z_{t} \geq 0$ if the income is at least $\sigma \Omega+\left(k_{0}-1\right)$ follows more generally from (8) and (10). If $z_{t}, t=1, \ldots, T$, is positive, and assuming $s_{t} \geq 0$, then it follows from (7) that the optimal consumption plan is increasing.

If the social comparison level or the initial adaptation level are sufficiently high, $\sigma \Omega+\left(k_{0}-1\right) a_{1}>I$, then the optimal solution involves some $z_{t}<0$. This can yield complex patterns of consumption. Recall that consumption below the reference level implies that the consumer operates on the convex part of the value function. Therefore, the consumer will find it optimal to accumulate as much loss as possible in some periods. To do so, the individual will cease consumption in some intermediate periods, with the hope of lowering the adaptation level. Once the reference level is low enough, he may start an increasing consumption plan from then on. Numerical methods can be used to obtain the optimal consumption plans in these complex cases.

In Figure 7, we present two possible optimal consumption plans for a fixed income of 100. In this example, $a_{1}$ is set to 0 and $S$ to 5 . In Figure 7a, the optimal consumption plan is increasing. Reference levels and experienced utility are also increasing. In Figure $7 \mathrm{~b}$, there is a greater weight given to social comparison; the optimal consumption plan, while still increasing, is flatter and shows the moderating effect of social comparison. In the extreme case, when the weight of social comparison is set to one, the optimal plan will be flat. 


\section{Figure 7}

Optimal Consumption Plan, and Associated Adaptation Level and Experienced Utility
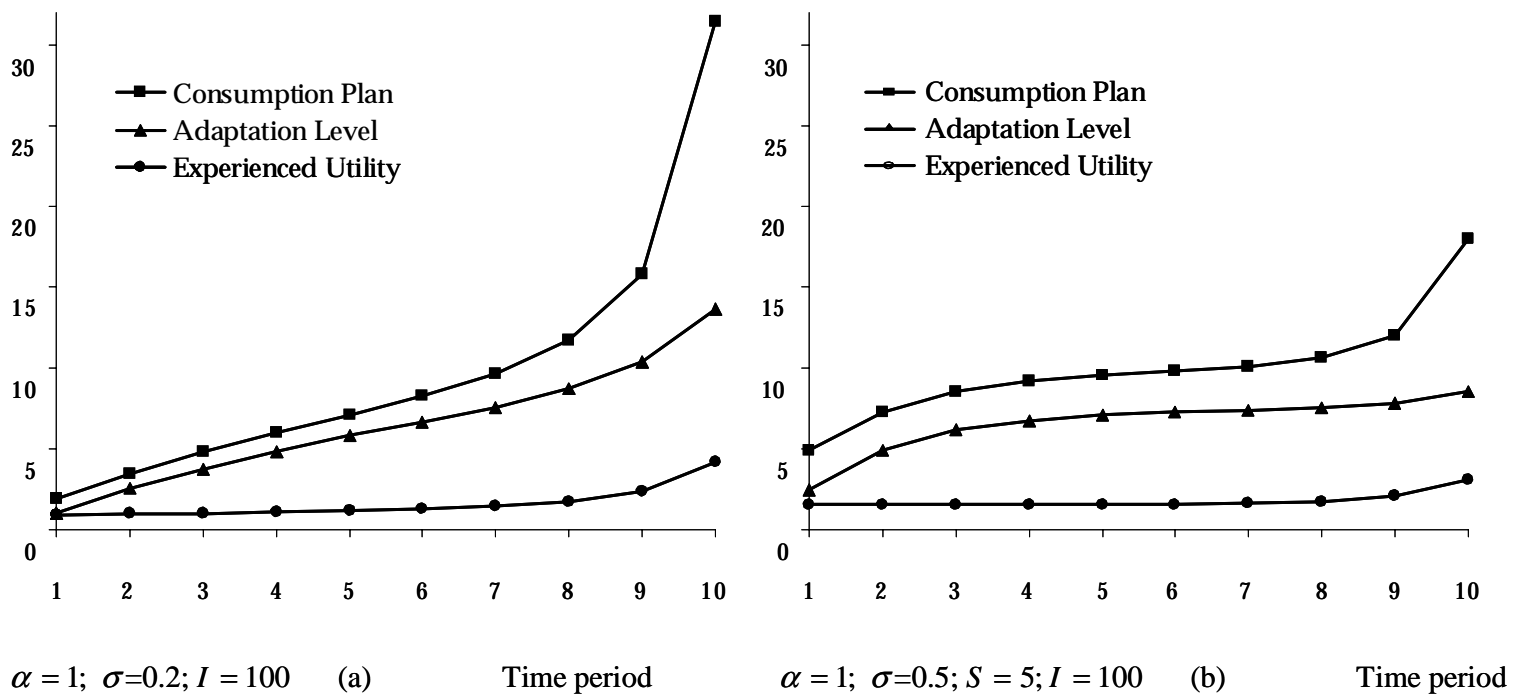

$\alpha=1 ; \sigma=0.2 ; I=100 \quad$ (a)

Time period

$\alpha=1 ; \sigma=0.5 ; S=5 ; I=100$

Time period

The key observation is that by anticipating the change in future reference levels induced by current consumption, a rational consumer could choose a consumption plan that may produce substantially higher total utility than a constant consumption plan (16.1 versus 12 when $\alpha=1$, $\sigma=0.2$, Figure 7a). For a high $\sigma$, the optimal plan becomes flatter and therefore the total utility under the optimal plan and the constant consumption plan are close (17.9 versus 17.0 when $\alpha=$ $1, \sigma=0.5$, Figure $7 b)$.

\section{Figure 8}

Utility of Income for Optimal Plan

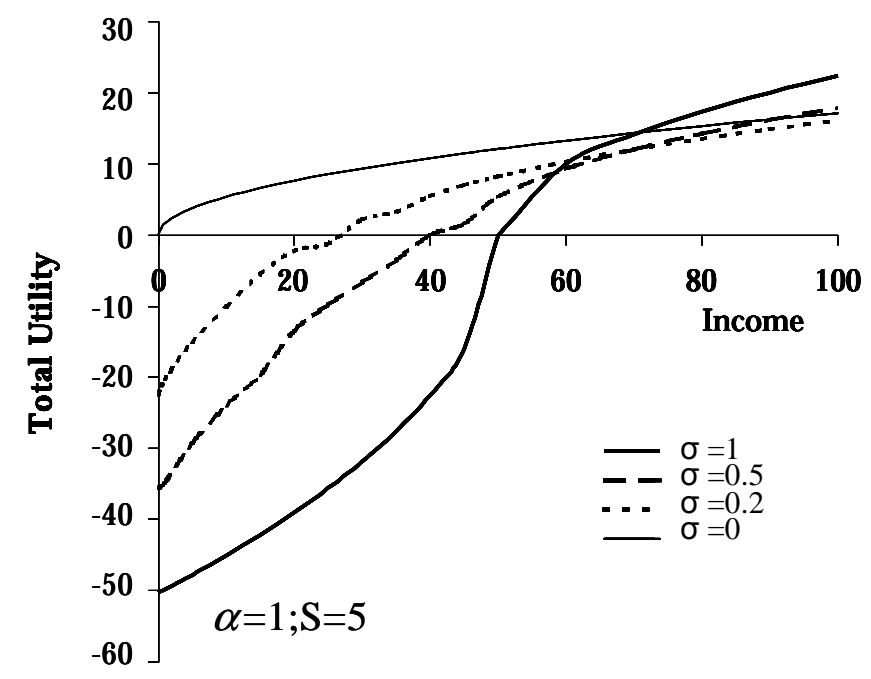

For a given income, $I$, we can solve the consumption planning problem and find the total utility associated with the optimal plan. By varying $I$, we can repeatedly solve the planning problem 
and derive the indirect utility of income. In Figure 8, indirect utility of income is plotted for some specific values of parameters. It is clear from this figure that an increase in income to a richer person provides less incremental utility than the same increase would provide for a poor person. It is of special interest to note that indirect utility of income need not always be Sshaped even if the per period utility function, $v$, is S-shaped.

For $\sigma=0$ there is no social comparison, and a rational consumer derives a positive total utility for all values of income. For example for $I=20$, the total utility is 7.7. A person with $I=20$ is relatively poor because with an average consumption of 2 units per period he cannot keep up with the social comparison level of 5 units per period. As $\sigma$ increases, his utility decreases. With $\sigma=1$ such a poor person obtains a high negative total utility of 39. In contrast, a rich person $(I=100)$ has a total utility of 17.1 for $\sigma=0$. Social comparison $(\sigma=1)$ also contributes to further increase his total utility to 22.4 .

\section{Figure 9}

Indirect Utility of Optimal vs. Constant Consumption Plan

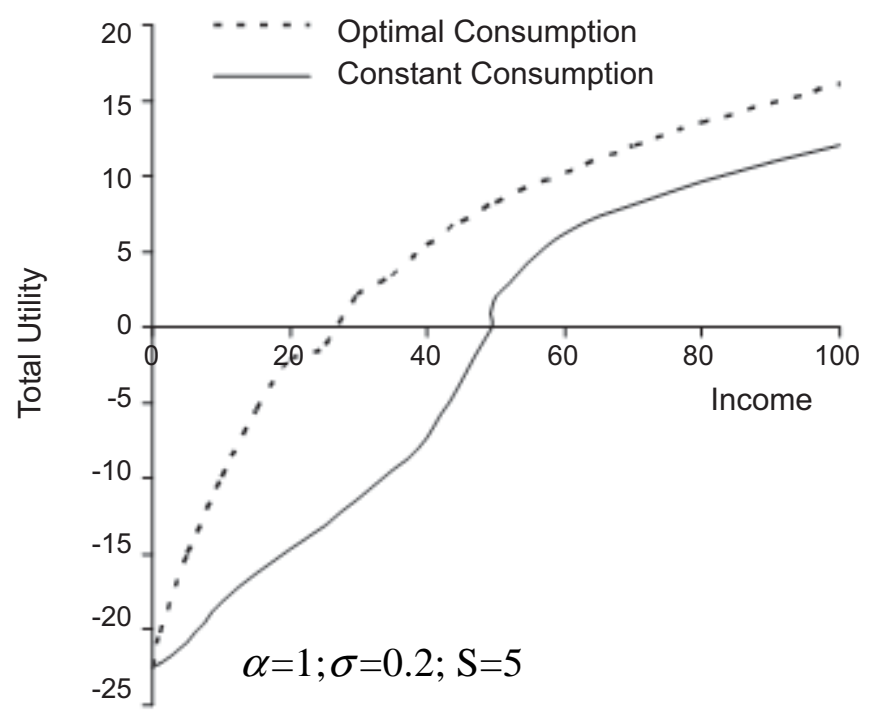

In Figure 9 we compare the utility derived from an optimal consumption plan with the utility derived from a constant consumption plan. As expected, the utility of the optimal plan is substantially higher than the utility of the constant consumption plan. Benefits of optimal planning seem to accrue more to relatively poorer people. For example, the gain in utility through optimal planning for a person with $I=40$ is substantially higher $[5.5-(-7.3)=12.8]$ than for a person with $I=60$ [10.3-6.3=4]. A person below the average income of 50, but above the threshold of a $\sigma \Omega+\left(k_{0}-1\right) a_{1}=32.1$, can carefully choose an increasing consumption plan that yields positive experienced utility in all periods. However, under constant consumption, such a person consumes below the reference level, except for the first period, thereby realizing negative experienced and total utility. 


\section{Predicted Versus Actual Happiness}

"The great source of both the misery and disorders of human life, seems to arise from over- rating the difference between one permanent situation and another."

- Adam Smith, “The Theory of Moral Sentiments," 1979, Part III, Chapter III

So far we have seen that our Adaptation-Social Comparison Model is consistent with empirical findings that within a country richer people are happier than poorer people (social comparison), but that over time well-being does not increase in spite of permanent increases in income for all (adaptation). But the puzzle that we stated at the start of the paper still needs resolution. Lottery winners may not be happier (Brickman, Coates and J anoff-Bullman, 1978), but most people continue to believe that winning a lottery will make them happier.

As we have demonstrated in Section 4, if people plan optimally, then more money indeed buys more happiness; though their happiness will increase at a diminishing rate. Optimal planning, however, requires that one should correctly predict the impact of current consumption on future utility. An increase in consumption has two perilous effects on future utility. First, the adaptation level goes up and therefore future experienced utility declines (e.g., people get used to a fancier car, a bigger house, or a vacation abroad). Second, the social comparison level may also go up, which again reduces experienced utility. When one joins a country club or moves to a more prosperous neighborhood, then the peer group with which social comparisons are made also changes. The individual now compares himself with more prosperous "Joneses" and comparisons to his previous peer group of less prosperous "Smiths" fades. If our lottery winner foresees all this, then he can appropriately plan consumption over time and realize high total utility in spite of a higher level of adaptation and an upward movement in peer group. The rub is that people underestimate adaptation and possibly changes in peer group. Loewenstein, O'Donoghue, and Rabin (2003) have documented and analyzed underestimation of adaptation and have called it projection bias.

Because of projection bias, a person will realize less happiness than he thinks. The gap between predicted and realized levels of happiness (total utility) further increases if one plans myopically rather than optimally. An example of a myopic plan is to allocate a budget or income equally in each period (constant consumption), as opposed to an increasing plan. A worse form of myopic planning would be to maximize immediate happiness through splurging (large consumption early on); which is what some lottery winners presumably end up doing.

We buy too much when hungry (Nisbett and Kanouse, 1968), forget to carry warm clothing during hot days for cooler evenings, predict that living in California will make us happy (Schkade and Kahneman, 1998) and generally project too much of our current state into the future and underestimate adaptation (Loewenstein and Schkade, 1999; Loewenstein, Read, and Baumeister, 2003; Gilbert, 2006). Van Praag and Frijters (1999) estimate a rise of between 35 and 60 cents in what one considers required income for every dollar increase in income. Stutzer (2003) also estimates an increase in adaptation levels of at least 40 cents for each dollar increase in income. After the very first year, the joy of a one dollar increase in income is reduced by $40 \%$, but people are unlikely to foresee this reduced contribution to happiness. People do qualitatively understand that some adaptation to change in lifestyle with higher income will take place; they simply underestimate the magnitude of the changes.

In our model, the chosen consumption plan determines the actual reference level, $r_{t}$, by means of (2) and (3). In every period, subjects observe the current reference level, but may fail to 
correctly predict the value of this state variable in future periods. According to projection bias, the predicted reference level is somewhere in between the current reference level and the actual reference level. The relationship between the actual and predicted reference levels can be modeled using a single parameter, $\pi$, as follows:

\section{Predicted Reference Level $=\pi$ (Current Reference Level) $+(1-\pi)($ Actual Reference Level $)$}

Thus, when $\pi=0$, then there is no projection bias and the predicted reference level coincides with the actual reference level. If $\pi=1$, then the person adopts the current reference level as the future reference level. An intermediate value of $\pi=0.5$ implies that the person's predicted reference level is halfway between the current and actual reference levels. The projection bias model can be extended to any state variables influencing preferences such as the satiation level (Baucells and Sarin, 2006a). If consumption stays above the actual reference level over time, then a person with projection bias may be surprised that the actual realized utility in a future period is lower than what was predicted. The reason, of course, is that the actual reference level is higher than anticipated. Actual happiness associated with higher levels of consumption may be much lower than what was hoped for. This gap may motivate the person to work even harder to increase his income in the hopes of improving happiness. But this chase for happiness through higher and higher consumption is futile as the reference level keeps on increasing.

To formalize these ideas, let $\tau$ be the current period. The actual and predicted reference levels for a subsequent period $t$ are $r_{t}$ and $\hat{r}_{\tau, t}$, respectively. Now,

$$
\hat{r}_{\tau, t}=\pi r_{\tau}+(1-\pi) r_{t},
$$

where $r_{t}$ follows the dynamics governed by (2) and (3). The actual utility is given by the chosen consumption plan according to the Adaptation-Social Comparison Model; however the chosen consumption plan might not be optimal under projection bias. The reason is that, in period $\tau$, the individual will maximize the predicted utility at $\tau$, given by:

$$
\hat{V}_{\tau}\left(x_{\tau}, x_{\tau+1}, \ldots, x_{T} r \mid r_{\tau}, \pi\right)=\sum_{t=\tau}^{T} v\left(x_{t}-\hat{r}_{\tau, t}\right)
$$

The difference between actual and predicted utility can be demonstrated by a simple example. Suppose a person plans a constant consumption of $\mathrm{x}$ units per period. In the first period, the utility realized is $v(x)$ if $r_{1}=0$. If his projection bias is extreme $(\pi=1)$, he will predict no changes in reference levels, $\hat{r}_{1,2}=\hat{r}_{1,3}=\cdots=\hat{r}_{1, T}=0$ and a utility of $v(x)$ for the second and remaining periods. But the actual reference level $r_{2}$ in Period 2 will be greater than 0 for any $\alpha>0$ and it will be $x$ for $\alpha=1$. Thus, the actual utility will be between $v(0)$ and $v(\mathrm{x})$ for any $\alpha>0, \pi>0$. The gap between the predicted and actual utility for Period 2 onward will be $v(x)-v(0)$ for the extreme case of $\alpha=\pi=1$. This is the sort of dilemma lottery winners face. Because of projection bias, they overrate the difference between their predicted and actually realized levels of happiness.

We now consider consumption planning under projection bias. We set $\pi=0.5$, fix the budget at $I=100$, assume no initial adaptation $\left(a_{1}=0\right)$, and set the social comparison level to $S=10$. A person with projection bias maximizes (13) at $\tau=1$. He obtains $\left(\hat{x}_{1,1}, \hat{x}_{1,2}, \ldots=\hat{x}_{1, T}\right)$ as the optimal plan where $\hat{x}_{\tau, t}$ is the consumption at time $t$ as planned at period $\tau$. In Table 3 , a consumption plan with projection bias for Period 1 is shown in the first row. This person implements $\hat{x}_{1,1}=5.8$ and now solves (13) again with a reduced budget of $I-\hat{x}_{1,1}=94.2$. The 
solution now gives $\left(\hat{x}_{2,2}, \hat{x}_{2,3}, \ldots=\hat{x}_{1, T}\right)$ and $\hat{x}_{2,2}=8.5$ is implemented (second row of Table 3 ). Note that the consumption in Period 2 is revised upward from 8.1 (Period 1 plan for Period 2) to 8.5. Upon reaching Period 3, the person realizes that the actual reference level is higher than what he had thought earlier, so he optimizes again with this new information. The available budget is now $I-\hat{x}_{1,1}-\hat{x}_{2,2}=85.8$. By repeatedly solving (13), we obtain $\left(\hat{x}_{1,1}, \hat{x}_{2,2}, \ldots=\hat{x}_{T, T}\right)$.

\section{Table 3}

Revision of Consumption Plans under Projection Bias $[\alpha=1 ; \sigma=0,2 ; \pi=0,5 ; S=10 ; I=100]$

\begin{tabular}{rr|rrrrrrrrrr|r}
$\mathrm{T} \backslash t$ & 1 & 2 & 3 & 4 & 5 & 6 & 7 & 8 & 9 & 10 & Budg. A \\
\hline 1 & $\mathbf{5 . 8}$ & 8.1 & 9.0 & 9.4 & 9.6 & 9.7 & 9.8 & 10.2 & 11.4 & 17.0 & 100 \\
2 & - & $\mathbf{8 . 5}$ & 9.5 & 10.0 & 10.1 & 10.2 & 10.3 & 10.5 & 11.1 & 13.9 & 94.2 \\
3 & - & - & $\mathbf{9 . 7}$ & 10.2 & 10.4 & 10.5 & 10.6 & 10.7 & 11.0 & 12.5 & 85.8 \\
4 & - & - & - & $\mathbf{1 0 . 3}$ & 10.6 & 10.7 & 10.8 & 10.8 & 11.0 & 11.8 & 76.0 \\
5 & - & - & - & - & $\mathbf{1 0 . 6}$ & 10.8 & 10.8 & 10.9 & 11.0 & 11.6 & 65.7 \\
6 & - & - & - & - & - & $\mathbf{1 0 . 8}$ & 10.9 & 10.9 & 11.0 & 11.4 & 55.1 \\
& 7 & - & - & - & - & - & - & $\mathbf{1 0 . 9}$ & 10.9 & 11.0 & 11.4 & 44.3 \\
8 & - & - & - & - & - & - & - & $\mathbf{1 1 . 0}$ & 11.0 & 11.4 & 33.4 \\
& 9 & - & - & - & - & - & - & - & - & $\mathbf{1 1 . 1}$ & 11.4 & 22.4 \\
& 10 & - & - & - & - & - & - & - & - & - & $\mathbf{1 1 . 4}$ & 11.4 \\
\hline Actual $\hat{x}_{\tau, \tau}$ & 5.8 & 8.5 & 9.7 & 10.3 & 10.6 & 10.8 & 10.9 & 11.0 & 11.1 & 11.4 & - \\
\hline \multirow{2}{*}{ Optimal $x_{t}^{*}$} & $\mathbf{2 . 5}$ & $\mathbf{4 . 5}$ & $\mathbf{6 . 1}$ & $\mathbf{7 . 5}$ & $\mathbf{8 . 7}$ & $\mathbf{9 . 8}$ & $\mathbf{1 0 . 9}$ & $\mathbf{1 2 . 3}$ & $\mathbf{1 4 . 7}$ & $\mathbf{2 3 . 1}$ & $\mathbf{1 0 0}$ \\
\hline
\end{tabular}

Note that the person with projection bias is forward looking and does plan optimally except for using his predicted reference levels in arriving at the consumption plan. A consequence of such a plan, for example, is that he may over-consume in early periods if he underestimates changes in future reference levels. So at an intermediate period, he has used up a lot more budget than he would have used had he predicted reference levels accurately. The projection bias consumption plan is therefore flatter than the optimal consumption plan under no projection bias. In Table 3, the projection bias plan (Actual $\hat{x}_{\tau, \tau}$ ) is compared to the optimal plan $\left(x_{t}^{*}\right)$. As expected, the person is over-consuming in early periods compared to the optimal plan. Under projection bias, the actual total utility (8.4) may be lower than the optimal total utility (11.7), and is much lower than the predicted total utility (21.1) in Period 1.

In Figure 10, the predicted and actual total utilities for different levels of income are shown. The difference between predicted and actual utility increases significantly as the projection bias increases from $\pi=0.5$ to $\pi=1$. It is clear that people think that more money will buy them a lot more happiness than it actually does. 


\section{Figure 10}

Utility of Income Under Projection Bias
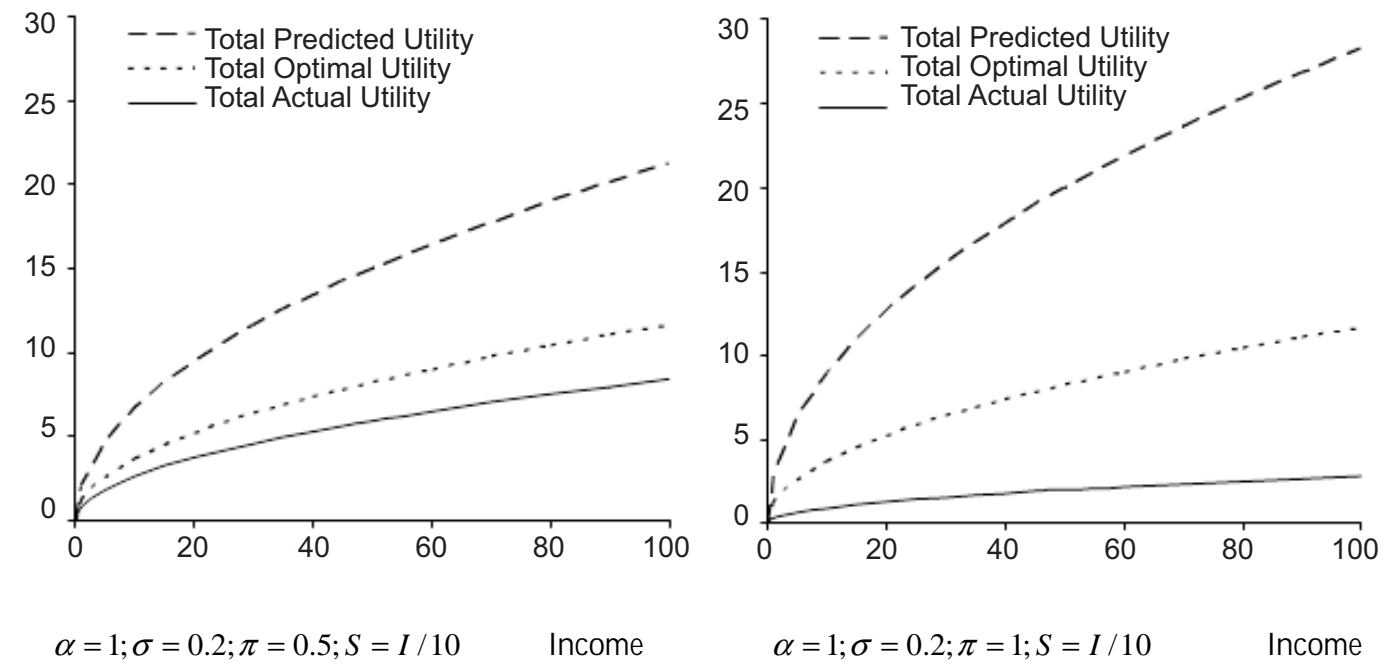

If we are wired to underestimate adaptation, then there is little we can do about our incorrect predictions of future state. But we can at least be forward looking and account for the effects of current consumption on future utility. A myopic planner who uses the heuristic of constant consumption will realize even less total utility and suffer from a bigger gap between predicted and realized happiness (Herrnstein and Prelec, 1992). Ironically, the DU model with no discounting will prescribe the same erroneous conclusion as the optimal consumption plan is flat, thereby realizing much less happiness than what would have been predicted and a great deal of disappointment.

\section{Happiness and Budget Allocation}

To gain further insight into the relationship between happiness and income, consider a simple model in which one allocates a fixed budget between two goods. The first good is an adaptive good, whereas the second good is a basic good for which the reference level remains constant. The overall utility is additively separable between the two goods. The optimization problem is:

$$
\begin{gathered}
\operatorname{Max} \sum_{t=1}^{T} w v\left(x_{t}^{a}-r_{t}^{a}\right)+(1-w) v\left(x_{t}^{b}-r^{b}\right) \\
\text { s.t. } \sum_{t=1}^{T} x_{t}^{a}+x_{t}^{b} \geq I
\end{gathered}
$$

Where $r_{t}^{a}$ is determined by the usual updating equation. If $\omega=1 / 2$, then the adaptive good, $A$, will provide less utility because reference levels increase due to past consumption. The basic good, $B$, provides a greater utility throughout as long as consumption is above its constant reference level $\left(r^{b}\right)$. 


\section{Figure 11}

Consumption of Adaptive (A) and Basic (B) Goods under Projection Bias. The reference level for Good $\mathrm{B}$ is set to $r^{b}=4$
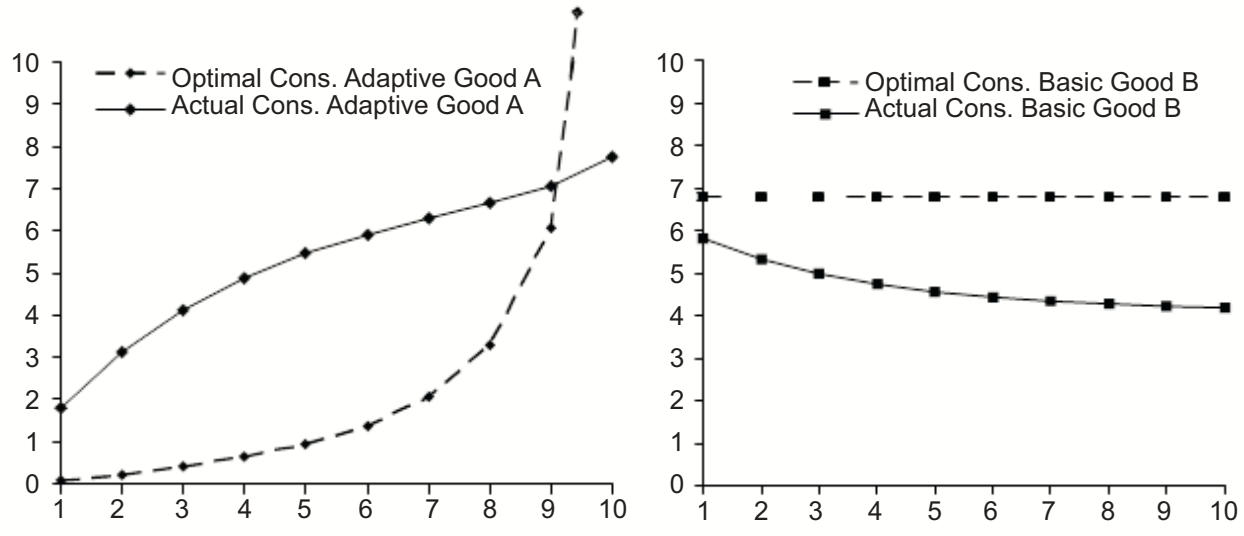

$$
\alpha=1 ; \sigma=0 ; \pi=0.5 ; w=0.67 \quad \text { (a) Period }
$$
$\alpha^{2}=0 ; \sigma=0 ; \pi=0.5 ; 1-w=0.33$
(b) Period

In Figure 11, the optimal allocation of a fixed budget of $I=100$ is compared to the allocation that results from projection bias. In this example, we set $r^{b}=4$; meaning, a per-period consumption of at least 4 units of the basic good is required to experience positive utility. For the optimal allocation, the adaptive good, $A$, receives a low allocation in early periods to keep reference levels under control. The consumption plan for Good $A$ is increasing over time (see Figure 11a). The basic good, $B$, in contrast, receives a constant income allocation of about 7 units per period (see Figure 11b).

Under projection bias, the person over-consumes the adaptive good, $A$, in early periods, which raises the reference levels for later periods. In order to keep up with the increased reference levels of Good $A$, more and more budget is allocated to it at the expense of the basic good, $B$. The total utility under projection bias is 8.2 units compared to the total utility of 12 units that is obtained under optimal planning.

\section{Table 4}

Fraction of Budget Allocated to Basic Good B

\begin{tabular}{|c|c|c|}
\hline Income & $\begin{array}{c}\text { Optimal } \\
(\%)\end{array}$ & $\begin{array}{c}\text { Under } \\
\text { Projection } \\
\text { Bias (\%) }\end{array}$ \\
\hline & & \\
40 & 94 & 91 \\
50 & 89 & 82 \\
60 & 82 & 79 \\
70 & 77 & 62 \\
80 & 73 & 56 \\
90 & 70 & 51 \\
100 & 68 & 47 \\
\hline
\end{tabular}


We can perform this analysis for several levels of income. Table 4 shows the relationship between income, $I$, and percent allocation of income to the basic good, $B$. Under the optimal plan, the percent allocation to the basic good decreases as income increases; this is also the case under projection bias. Under projection bias, however, a far smaller percentage of income (compared to the optimal plan) is allocated to the basic good. As shown in Figure 12, the net result is that the actual realized utility at every income level is lower. This misallocation is even greater for higher levels of income as realized utility becomes flatter as income increases.

No one would shed a tear if the rich realized less total utility because they overspent on fancy cars, luxury houses or expensive hotels. A consequence of projection bias, though, is that even for poorer segments of society, a greater than optimal allocation is made to addictive goods such as alcohol, drugs and lottery tickets, thereby leaving them with less of their budget for basic goods such as nutritious food and hygiene.

\section{Figure 12}

Utility of Income for Two Goods Under Projection Bias

- - - - Total Optimal Utility

Total Utility under Projection Bias

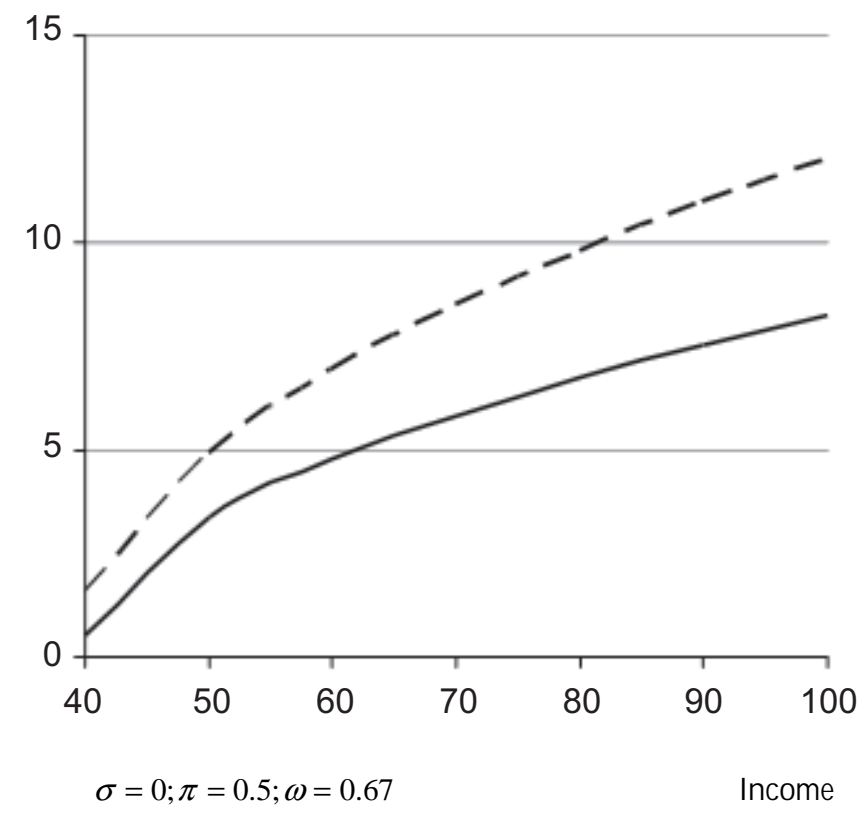




\section{Conclusions}

In this paper, we have proposed a model of adaptation and social comparison for valuing time streams of consumption. This model explains two widely observed empirical findings in the well-being literature. The first empirical finding is that within a society richer people are happier than poorer ones. The second finding is that for a given country, average well-being has not improved over time in spite of large gains in per capita income. The second finding is not universal, since in some countries (e.g., Italy and Denmark) the average well-being has improved, though in the majority of countries, including the United States, there has not been an appreciable increase in average well-being.

At the individual level, well-being even for lottery winners who had won from $\$ 50,000$ to $\$ 1,000,000$ within the previous year was rated at an average of 4 points, compared to 3.8 points for a control group, on a 5-point scale. Further, these lottery winners rated daily activities as less pleasurable than the control subjects did. This finding is dramatic and counterintuitive as most people believe that they would be happier if they won the lottery or even obtained a $20 \%$ raise in income.

We therefore posed a slight modification to the Easterlin puzzle: Why do people believe that more money will buy more happiness when in fact it does not? We show that under projection bias this puzzle is resolved as a person will predict much more happiness than he will actually realize because of his failure to account for changes in reference levels that accompany higher levels of consumption.

Finally, we show that a greater emphasis on basic goods, rather than adaptive goods, will improve happiness. Basic goods include food, shelter, sleep, friendship, spiritual activities, etc. Great discipline is required, however, to give adequate importance to basic goods. Projection bias will divert resources from basic goods toward adaptive goods even under rational planning. It might be interesting to examine whether activities that provide a better perspective on life (meditation or other spiritual practices) would be able to reduce projection bias in some cases. 


\section{References}

Baucells, M., and R. Sarin (2006a), "Predicting Utility under Satiation and Habituation," Barcelona, IESE Business School.

Baucells, M., and R. Sarin (2006b), "Satiation in Discounted Utility," forthcoming in Operations Research.

Brickman, P., D. Coates, and R. J anoff-Bullman (1978), "Lottery Winners and Accident Victims: Is Happiness Relative?," Journal of Personality and Social Psychology, 36, pp. 917-927.

Clark, A . (1996), "J ob Satisfaction in Britain," British Journal of Industrial Relations, 34, pp. 189-217.

Davidson, R., and colleagues (2003), "Alterations i Brain and Immune Function Produced by Mindfulness Meditation," Psychosomatic Medicine, pp. 65, 564-270.

Davidson, R., D. Jackson, and N. Kalin (2000), "Emotion, Plasticity, Context, and Regulation: Perspectives from Affective Neuroscience," 126, pp. 890-906.

Davis, J., T. Smith, and P. Marsden (2001), "General Social Survey, 1972-2000, Cumulative Codebook," Roper Center for Public Opinion Research, Storrs, CT.

Diener, E., and W. Tov (2005), "National Subjective Well-Being Indices: An Assessment," in "Encyclopedia of Social Indicators and Quality-of-Life Studies," ed. by K. Land. Springer, New York.

DiTella, R., and R. MacCullouch (2006), "Some Uses of Happiness Data in Economics," Journal of Economic Perspective, 20(1), pp. 25-46.

Easterlin, R. (1974), "Does Economic Growth Improve the Human Lot? Some Empirical Evidence in Nations and Households," in "Economic Growth: Essays in Honor of Moses A bramovitz," ed. by P. David, and M. Redner, A cademic Press, New York, pp. 98-125.

Easterlin, R. (1995), "Will Raising the Incomes of All Increase the Happiness of All?," Journal of Economic Behavior and Organization, 27, pp. 35-48.

Easterlin, R. (2001), "Income and Happiness: Towards a Unified Theory," Economic Journal, 111, pp. 465-484.

Frank, R. (1985), "Choosing the Right Pond," Oxford University Press, New York.

Frank, R. (1997), "The Frame of Reference as a Public Good," The Economic Journal, 107 (445), pp. 1832-1847.

Frank, R. (1999), "Luxury Fever: Why Money Fails to Satisfy in an Era of Excess," The Free Press, New York.

Frederick, S., and G. Loewenstein (1999), "Hedonic Adaptation," in "Well Being: The Foundation of Hedonic Psychology," ed. by D. Kahneman, E. Diener, and N. Schwarz, Russell Sage, New York, pp. 302-329.

Frey, B., and A. Stutzer (2002a), "Happiness and Economics," Princeton University Press, Princeton. 
Frey, B., and A. Stutzer (2002b), "What Can Economists Learn from Happiness Research," Journal of Economic Literature, 40 (2), pp. 402-435.

Gilbert, D. (2006), "Stumbling on Happiness," Knopf, New York.

Herrnstein, R., and D. Prelec (1992), "A Theory of Addiction," in "Choice Over Time," ed. by G. Loewenstein and J. Elster, Russell Sage Foundation, New York.

Inglehart, R., and colleagues (2000), "World Values Surveys and European Values Surveys," 1981-1984, 1990-1993, 1995-1997, Institute for Social Research, Ann Arbor.

Inglehart, R., and H.-D. Klingemann (2000), "Genes, Culture, Democracy, and Happiness," in "Culture and Subjective Well-Being," ed. by E. Diener and E. Suh, MTT Press, Cambridge, MA.

Kahneman, D., E. Diener, and N. Schwarz (eds.) (1999), "Well Being: The Foundation of Hedonic Psychology," Russell Sage Foundation, New York.

Kahneman, D., and A. Krueger (2006), "Developments in the Measurement of Subjective WellBeing," Journal of Economic Perspectives, 20 (1), pp. 3-24.

Kahneman, D., A. Krueger, D. Schkade, N. Schwarz, and A. Stone (2006), "Would You Be Happier if You Were Richer? A Focusing Illusion," Science, 312 (30), pp. 1776-1780.

Kahneman, D., and D. Miller (1986), "Norm Theory: Comparing Reality to its Alternatives," Psychological Review, 93 (2), pp. 136-153.

Kahneman, D., and A. Tversky (1979), "Prospect Theory: An Analysis of Decision under Risk," Econometrica, 47 (2), pp. 263-291.

Kahneman, D., P. P. Warker, and R. K. Sarin (1997), "Back to Bentham? Explorations of Experienced Utility," The Quarterly Journal of Economics, 112 (2), pp. 375-405.

Koopmans, T. C. (1960), "Stationary Ordinal Utility and Impatience," Econometrica, 28 (2), pp. 287-309.

Layard, R. (2005), “Happiness: Lessons from a New Science,” The Penguin Press, London.

Lepper, H. (1998), "Use of Other-Reports to Validate Subjective Well-Being Measures," Social Indicators Research, 44, pp. 367-379.

Loewenstein, G., T. O'Donoghue, and M. Rabin (2003), "Projection Bias in Predicting Future Utility," The Quarterly Journal of Economics, 118 (3), pp. 1209-1248.

Loewenstein, G., D. Read, and R. Baumeitster (2003), "Decision and Time," Russell Sage Foundation, New York.

Loewenstein, G., and D. Schkade (1999), "Wouldn't It Be Nice: Predicting Future Feelings," in "Well Being: The Foundation of Hedonic Psychology," ed. by D. Kahneman, E. Diener, and N. Schwarz, Russell Sage, New York, pp. 85-108.

Medvec, V., S. Madey, and T. Gilovich (1995), "When Less Is More: Counterfactual Thinking and Satisfaction Among Olympic Medalists," Journal of Personality and Social Psychology, 69, pp. 603-610. 
Morawetz, D. (1977), "Income Distribution and Self-Rated Happiness: Some Empirical Evidence," Economic Journal, 87, pp. 511-522.

Nisbett, R. E., and D. E. Kanouse (1968), "Obesity, Hunger, and Supermarket Shopping Behavior," Proceedings of the Annual Convention of the American Psychological Association, 3, pp. 683-684.

Parducci, A. (1995), "Happiness, Pleasure, and Judgment: The Contextual Theory and its Applications," Erlbaum, Hove, England.

Pavot, W., and E. Diener (1993), "The Affective and Cognitive Cortex of Self-Reported Measures of Subjective Well-Being," Social Indicators Research, 28 (1), pp. 1-20.

Pollak, R. (1970), "Habit Formation and Dynamic Demand Functions," Journal of Political Economy, 78, pp. 745-763.

Ryder, H. E., and G. M. Heal (1973), "Optimal Growth with Intertemporally Dependent Preferences," Review of Economic Studies, 40, pp. 1-33.

Samuelson, P. (1937), "A Note on Measurement of Utility," Review of Economic Studies, 4, pp. 155-161.

Schkade, D., and D. Kahneman (1998), "Does Living in California Make People Happy? A Focusing Illusion in Judgments of Life Satisfaction," Psychological Science, 9 (5), pp. 340-346.

Smith, D., K. Langa, M. Kabeto, and P. Ubel (2005), "Health, Wealth, and Happiness," Psychological Science, 16 (9), pp. 663-666.

Solnick, S., and D. Hemenway (1998), "Is More Always Better? A Survey on Positional Concerns," Journal of Economic Behavior and Organization, 37, pp. 373-383.

Stutzer, A. (2003), "The Role of Income Aspirations in Individual Happiness," Journal of Economic Behavior and Organization, 54, pp. 89-109.

Van Praag, B. M., and A. Ferrer i Carbonell (2004), "Happiness Quantified: A Satisfaction Calculus A pproach," Oxford University Press, Oxford, UK.

Van Praag, B. M., and P. Frijters (1999), "The Measurement of Welfare and Well-Being: The Leyden Approach," in "Well Being: The Foundation of Hedonic Psychology," ed. by D. Kahneman, E. Diener, and N. Schwarz, Russell Sage, New York, pp. 413-433.

Wathieu, L. (1997), "Habits and the Anomalies in Intertemporal Choice," Management Science, 43 (11), pp. 1552-1563.

Wathieu, L. (2004), “Consumer Habituation," Management Science, 50 (5), pp. 587-596. 